\title{
Pedagogia e máscaras: Entrevista com dois mestres canadenses
}

Vilma Campos dos Santos Leite ${ }^{1}$

É no contexto do pós-doutoramento intitulado Brincantes mascarados da cultura popular: possibilidades para a formação do artista cênico na contemporaneidade que insiro as duas entrevistas a seguir. A primeira aconteceu no início de 2016 na UFMG em Belo Horizonte, quando Steve Jarand ${ }^{2}$ trouxe um workshop de máscaras expressivas durante três dias e organizado por Mariana Muniz, que foi também a tradutora no momento da entrevista.

A segunda aconteceu com Sue Morrison ${ }^{3}$ no início de 2017 em Toronto - Canadá, quando finalizei um workshop de Clown Through Mask. Para esse momento foram fundamentais as participações de Isaac Luy como tradutor e Mayara Gabaldi no registro em áudio e transcrição do diálogo na língua inglesa ${ }^{4}$.

Steven atua em Calgary e Sue em Toronto, mas os dois mestres sistematicamente oferecem o processo de formação em outros países. São duas perspectivas bem diferenciadas de trabalho, uma vez Steven parte um naipe de máscaras que reflete expressões humanas recorrentes a partir de seu estudo prévio, enquanto o de Sue prevê um processo criativo de confecção e utilização da máscara a partir do "eu" e visando ao palhaço de cada um.

Apesar das duas perspectivas canadenses serem distintas, acabam se complementando dentro do meu estudo por dois motivos principais. Primeiramente porque trazem aspectos que não estão limitados a matriz recorrente na minha prática docente até então de iniciação de estudantes de teatro na linguagem da máscara a partir da utilização de máscara neutra ou de máscaras de Commedia dell'Arte.

A outra razão é a partir de algumas similitudes entre essas duas propostas. Ambas consideram a emoção como aspecto relevante no processo de utilização da máscara e possuem em sua origem algum contato com o trabalho de improvisação de Keith Johnstone. Keith e outros artistas da Improv têm um solo já bastante cultivado no Canadá e a atuação de Steve Jarand e de Sue Morrison nesse país não me parece uma coincidência, mas não é aqui que vou aprofundar essa afirmação. Proponho-me a compartilhar trechos da entrevista realizada com Steven Jarand
1.

Pós-doutorado no Programa de Pós-Graduação em Artes da Cena da Unicamp (PNPD/ CAPES), sob supervisão da Prof. Dra. Suzi Frankl Sperber. Professora na Universidade Federal de Uberlândia. ORCID: http://orcid.org/ 0000-0002-8440-881] Contato:

leitevilma2008@hotmail.com

2.

Maiores informações sobre Steve Jarand, em seu site: http://stevejarand.com/

3.

Maiores informações sobre Sue Morrison, em seu site: http://canadianclowning.com/

4.

A tradução não é literal e procurou preservar o tom coloquial da oralidade. 
e Sue Morrison porque compreendo que são depoimentos relevantes, independentemente dos objetivos mais específicos que tive ao realiza-las, ou seja, de lançar luzes para a pesquisa que realizo envolvendo abordagens metodológicas para a aprendizagem em máscara.

\section{Entrevista com Steve Jarand}

VILMA - Gostaria muito de saber se você confecciona as máscaras dos seus workshops e qual a inspiração para elas.

STEVE - Sim, em Calgary, no Canadá, todo ano eu conduzo um workshop de cinco dias em que os participantes confeccionam máscaras e jogam com as máscaras. Atualmente meu processo é bastante prático. Eu tenho uma coleção de máscaras e, à medida que percebo que existem algumas emoções, algumas sensações que não estão fazendo parte dessa coleção, eu vou trabalhando nelas. E, para além disso, é bastante comum começar a partir de um elemento, como, por exemplo - olhos redondos ou um grande nariz. É a partir dessas formas que vou criando, ou seja, é algo que vai integrando depois desses elementos que eu escolho.

VILMA - Qual o perfil das pessoas que buscam os seus workshops?

STEVE - Normalmente eu tenho atores e não atores misturados nas turmas. E, geralmente, as pessoas que têm algum trabalho anterior com atuação e que sabem liberar-se de si mesmos conseguem fazer trabalhos mais fortes com as máscaras do que pessoas que não possuem essas ferramentas trabalhadas. Mas sempre há exceções. Muitas vezes com não atores não há nenhum tipo de expectativa por parte deles, e então eles podem ser livres e bastante honestos com a máscara. Algumas vezes, quando trabalho com atores que já atuam com alguma máscara, como por exemplo o clown, têm muita dificuldade de sair do padrão de trabalho deles, inclusive com a comédia. Aqui estou achando muito interessante porque sei que as pessoas quase todas têm uma formação e atuação anteriores. Fiquei impressionado porque todo mundo procurou relaxar e abandonar esses conhecimentos prévios e se introduzir na máscara. Senti que ninguém estava querendo "plugar" o próprio show, ou seja, fazer o que já sabe de melhor dentro da máscara.

VILMA - Percebi que no seu trabalho da oficina há uma influência forte do trabalho de Impro do Keith Johnstone. Quais as associações que vocêfaz entre a abordagem de Viola Spolin e Keith Jonstone no campo da improvisação? 
STEVE - Eu não li todos os livros da Viola Spolin, apenas partes deles. Apesar disso, o que eu sinto do trabalho da Viola Spolin é que o foco é o grupo, como ele se relaciona, e descobrir coisas enquanto estão realizando os exercícios. Como o grupo consegue ser generoso e trabalhar como coletivo. Não é um trabalho em busca de histórias ou resultados. É mais um trabalho de exploração desses elementos. Eu acho que é diferente do Keith que está interessado na história, na apresentação pública e em oferecer aos espectadores a oportunidade de descobrir novas coisas a cada apresentação. A maior parte dos exercícios do Keith é mostrar para os jogadores como o jogo funciona e isso na frente dos espectadores. Para ele, isso já é suficientemente interessante. Descobrir como um jogo funciona, ou seja, o seu mecanismo. A maioria dos jogos do Teatro Esporte que é um dos formatos que o Keith criou. São quase os mesmos jogos que nós estamos fazendo aqui no workshop. São jogos com as mesmas dificuldades, sem as pessoas saberem exatamente o que devem fazer. Então os diretores explicam isso para os expectadores e eles vêm esses mesmos exercícios porque existe uma estrutura dramatúrgica nos jogos, que é algo muito importante de ser explorado.

Uma coisa que eu acho muito interessante quando eu estou conduzindo workshops é experimentar os jogos, mais além da superfície. Encontrar outros ângulos, outros pontos de vista que um mesmo jogo pode trabalhar e que eu não tinha descoberto antes.

VILMA - A sensação que eu tenho inclusive é que você vai selecionando a sequência dos jogos a partir do como se desenvolve o grupo.

STEVE - Eu gostaria de conseguir isso o tempo todo e partir do que vai acontecendo. Mas o que realmente acontece é que eu tento buscar o maior número de informações sobre o grupo. Como, por exemplo - que tipo de pessoas estão trabalhando, qual o perfil, e aí junto com coisas que eu quero experimentar. Então, se eu tiver boa sorte, alguma coisa acontece e eu vou precisar adaptar o que eu tinha planejado, e quando isso acontece é melhor ainda.

VILMA - Como você vê a relação entre gênero e máscara.

O gênero cômico é mais forte em seu trabalho?

STEVE - As máscaras inteiras são normalmente conhecidas ou associadas tradicionalmente como máscaras trágicas. Mas eu acho que da mesma forma como acontece na improvisação, na Impro, quando as pessoas estão fazendo alguma coisa cômica elas recebem um feedback imediato do público e isso acaba predominando em alguns momentos. Fazendo essa comparação com a improvisação, na máscara também é comum 
uma empatia muito grande com a comédia, mas é muito interessante atingir alguns estados dramáticos nela.

VILMA - Agora não é bem uma pergunta, mas sim uma observação. Em seu workshop você não traz informações prévias sobre as máscaras, como vemos quando se introduz, por exemplo, máscaras de Commedia dell'Arte, quando se explica primeiro um pouco sobre essa ou outras máscaras em uso. O que você traz é o espelho. Confesso que eu tinha até um certo preconceito com relação ao uso desse objeto, mas vim para o workshop justamente porque, sendo uma pessoa que trabalha com máscara, acho importante conhecer outras abordagens que não as que utilizo ou nas quais fui iniciada.

STEVE - Sobre as máscaras inteiras eu penso que é um trabalho bem sensitivo. O importante é vestir a máscara e ver outras pessoas vestirem as máscaras. Para ver que tipo de corpo, de estado fazem com que essa máscara se integre e aprender a partir do que se vê. Eu acho que, na verdade, eu tenho que adaptar o que eu faço com a máscara específica, porque o foco é aquela máscara específica e não é uma metodologia para todas.

Sobre a Commedia dell'Arte é completamente diferente porque tem uma tradição muito grande com relação às formas. Dependendo da forma da máscara, essa forma tem que ir junto com o corpo, com a situação, como você descreveu. E isso faz com que as máscaras da Commedia Dell'Arte, do material, do objeto fiquem cada vez mais estilizadas. Isso não é uma coisa ruim.

\section{Entrevista com Sue Morrison}

VILMA - Eu gostaria de saber se antes de encontrar Richard Pochinko, se houve alguma outra influência, talvez Keith Johnstone, ou outra pessoa que pode ter contribuido ensinando sobre performance, clown, ou coisas nesse sentindo.

SUE - Eu estava morando no Oeste do país e tinha um excelente programa de TV que chamava Saturday Night. E era tão novo e interessante, sempre tinha risco, era comédia ao vivo e totalmente diferente. E quando eu assisti, eu pensei - eu posso fazer isso. Eu me lembro de ver um episódio, acho que foi em 1978, o que as pessoas faziam era incrível. Eu não sabia bem o que era aquilo. Então eu resolvi vir para Toronto. E um amigo me disse "- Oh, Sue, você é tão divertida, você deveria fazer um workshop de improvisação. E eu fiz, mas o professor, agora eu sei, não era legal. Mas eu encontrei algo e eu senti que era aquilo que eu tinha que fazer na vida. Então eu comecei a estudar em um lugar chamado Second City, eles tinham muito bons professores lá. E eu senti que foi uma grande mudança na minha vida. Eu 
tinha vinte quatro ou vinte e cinco anos. Eu continuei a trabalhar e eu estava indo muito bem. Foi um período em que havia pessoas adoráveis trabalhando lá, grandes nomes. Eu tive muita sorte, eu realmente tive grandes professores de improv porque a filosofia desses professores era criar personagens, contar histórias e se envolver, nunca fazer piadas ou fazer graça. E então o Keith Johnstone veio para a Toronto e eu fiz um workshop com ele e primeiro o workshop pela manhã fazíamos tai chi e à tarde nós fazíamos improv. E então eu não entendia, mas era a filosofia dele despertar o corpo físico, mantê-lo acordado e não usar somente o cérebro. E foi um workshop maravilhoso, porque novamente, não era fazer uma piada, e sim o desenvolvimento de uma peça. Depois eu comecei a fazer teatro esporte, vários tipos. Participei da primeira trupe só de mulheres improvisadoras. Em vez de utilizar a mulher como um adereço na cena, nós buscávamos termos uma importância legítima. E eu fiz muito sucesso, mas uma hora eu me perguntei e se eu trabalhasse a partir do meu coração e não a partir da minha cabeça? E um dia saindo do teatro eu vi um pequeno cartaz que tinha o rosto do Richard Pochinko e dizia - Clown Through Mask. Eu não gostava de palhaços, eu odeio palhaços porque eu tive uma experiência ruim com um palhaço, foi uma festa de aniversário ou algo no circo, mas eu estava interessada em máscara.

VILMA - Então, você não sabia no momento que o Richard estava trabalhando com emoções.

SUE - Não, ninguém conhecia ele. Bem, exceto o pequeno grupo que estava trabalhando com ele.

VILMA - Parece-me interessante que de alguma maneira você respondeu a um chamado.

SUE - Absolutamente. Foi um momento de reconhecimento. Eu fui para a aula e eu me senti em casa. Mesmo sem eu saber nada sobre o trabalho do Richard, porque também eu não tinha uma história com o teatro antes disso.

VILMA - Você trabalhou muito tempo com ele?

SUE - Eu ainda trabalho com ele. Absolutamente. Eu nunca parei de trabalhar com ele mesmo depois que ele morreu.

VILMA - Quantos anos foram, enquanto ele era vivo?

SUE - Eu não sei. Eu tenho que olhar as datas e livros, mas sei que foram anos. Eu fiz workshops com ele e também shows que ele dirigiu... Eu acreditei nele e eu faria qualquer projeto com ele.

VILMA - Por que ele escolheu você? Ele poderia ter escolhido outra pessoa para trabalhar com ele. 
SUE - Bem, eu não sei. Eu posso perguntar - o que você acha? (ela ri) Porque eu acho que o Richard tinha a capacidade de ver o potencial das pessoas antes mesmo delas verem essa potencialidade.

VILMA - Havia outras pessoas que trabalharam com ele. Agora, há outras pessoas que fazem esse tipo de trabalho ou você é a única?

SUE - Há algumas pessoas fazendo variações do trabalho, provavelmente. Eu sei que ele tinha duas aprendizes, eu e uma mulher que eu acredito que foi para Oxford e fez o doutorado dela sobre drama terapia e usou essa base para o trabalho. E também o Ian Wallace que foi seu parceiro por um longo tempo, um amigo, eles trabalharam juntos e ele tentou encontrar a sua própria maneira de trabalhar, ele não ensinou por muito tempo, mas ele ensina agora. Há algumas coisas estranhas sobre ele escritas na internet que eu não gosto, porque o Richard não queria falar muitas coisas, há coisas que são colocadas como normal, eu não sei se ele gostaria disso, mas isso é só o que eu penso.

VILMA - O workshop que o Richard fazia tem o mesmo formato, a mesma duração que você trabalha?

SUE - Bem, eu estava pensando sobe isso ontem. Agora virou um pouco mais intenso, se é que é possível falar isso. Ele dava o exercício e deixava você experimentando e ele ia embora. Eu tenho um envolvimento com cada pessoa. Eu acho que uma das razões que ele pediu para eu continuar o trabalho, é que eu tinha um conhecimento de improv. De estrutura, de desenvolvimento de uma cena. E o Richard queria muito que o trabalho fosse mais performático, para ser apresentado em um teatro.

VILMA - Você fala que o Richard queria fazer um clown para hoje, o clown que falasse para o hoje. As pessoas mudam e o mundo muda, a metodologia está se renovando também?

SUE - Sim, absolutamente. Porque eu desejo, que este trabalho não se torne um dogma. Eu quero que o trabalho vá mudando. Que o trabalho se desenvolva e evolua na medida que as formas de comunicação evoluem também e a forma de se relacionar muda e afeta o trabalho. Mesmo, um exemplo, é o jeito da gente se vestir hoje. Estou sentindo que quase não preciso mais usar as caixas de figurinos. A última vez que fiz Joe e August ${ }^{5}$, não usei a caixa de figurinos. E outro exemplo é quando o Richard ensinava e a gente não podia falar em uma Turn. Mas eu estou vendo mais e mais com o tempo que as pessoas falam em uma Turn. E eu tenho que permitir coisas se adicionarem ao trabalho, isso se ajuda, se conecta.

VILMA - Você sabe de que etnia indígena o Smith, o mestre dele?
5 .

Workshop na sequência do Clown Through Mask 
SUE - Eu não gosto de falar muito disso, porque soa estranha. Porque o John Smith não era uma pessoa, era um espírito. E o Richard nunca falava muito sobre isso.

VILMA - E a influência do Philippe Gaulier, onde ele entra nessa história?

SUE - Depois. Eu fiquei muito feliz quando ele veio, porque um dos meus antigos parceiros de clown estava indo para Montreal para fazer este workshop então ele me disse: "Por que você não vem fazer?" E eu disse, "não sei... Eu não falo francês". Havia dois workshops: O Jogo e Bufão. No fim, meu parceiro não foi e eu fui. Eu não sabia o que eu ia encontrar lá. Eu sentia que eu não podia entender nada.

Eu não me lembro, mas eu acho que foi em 1980 ou algo assim, Philippe Gaulier não era muito conhecido. E no primeiro dia, o organizador do workshop falou para mim " - Mesmo que ele mandar você descer do palco, tenta voltar de novo e subir quantas vezes você puder." E naquele momento em Quebec, politicamente, "sem inglês". Agora há uma lei que prevê a não tradução de sinais em Inglês em lugares públicos. Então, eu não conhecia ninguém, as pessoas não eram do tipo " - Você não entendeu alguma coisa? Posso ajudar em alguma coisa?" Não, eu tentava, mas eu não entendia o que estava acontecendo. Eu levantava, eu sentava. Tentei algumas coisas. Eu não sabia o que ele estava pedindo para as pessoas fazerem, mas eu levantava, e uma vez eu sentei, ele disse alguma coisa e todo mundo riu. Então eu perguntei para alguém "- Desculpe-me o que o Philippe disse?" Eu não estava entendendo nada. Ah, ele disse "- Que você é muito chata!' E então, logo depois nós tivemos uma pausa para o almoço, todo mundo saiu, e eu fiquei sozinha chorando no quarto com os casacos e eu pensei em desistir e ir embora. E então o organizador chegou e ele disse: - O Philippe quer conversar com você. Eu disse - Sim. E o Philippe não falava Inglês. Ele falava em Francês e o organizador traduziu muita coisas que ele falou como "- Você tem alguma coisa nos olhos que eu gosto." E então eu pensei, "- Bem, talvez eu fique”.

Então eu fiquei trabalhando e eu consegui sucesso algumas vezes. Uma vez o Philippe subiu no palco e fez uma improvisação comigo e nós nos divertimos muito, foi muito divertido mesmo, muito louco.

VILMA - Nesse período, você ainda não dava workshop?

SUE - Não, eu era assistente do Richard naquela época, talvez era isso, mas eu não ensinava.

VILMA - Os jogos iniciais que vocêfaz no seu trabalho, Richard também fazia? 
SUE - Sim, Philippe Gaulier. Mas novamente, eu faço diferente do Philippe.

VILMA - Mas o Richard não fazia esses jogos?

SUE - Não esses jogos você pode fazer de uma maneira diferente e aí vira outra coisa. Uma forma diferente. Foi o que aconteceu como Richard ele foi ao Lecoq e o Lecoq disse: "- Volte para casa e faça o trabalho da sua maneira." Richard usou alguns exercícios, mas ele se apropriou dos mesmos.

SUE - Eu quero dizer que eu fiz mais que um workshop com o Philippe, que eu costumava trazer ele algumas vezes a Toronto. Eu estudei com ele em London, ele também me chamava para participar dos shows dele.

VILMA - Eu gostaria de saber, se possivel, que você falasse sobre o livro, e também sobre Verônica Coburn', se ela fez o workshop.

SUE - Sim, a Verônica fez o workshop. Ela era uma palhaça reconhecida na Irlanda e ela ficou maravilhada com o trabalho. Então ela voltou e fez Joe e August, e então ele me perguntou se eu tinha escrito sobre o processo. Eu tinha começado a escrever um livro, nós começamos, mas nós nunca terminamos. Eu nunca tive um impulso para escrever um livro. Eu não estava certa porque você escreve algo como um acadêmico. Eu não gosto de acadêmicos. Eu sinto muito. Eles tentam compartimentar, definir, rotular...E o clown é um anarquista, então quando você faz isso, você coloca numa caixa. É a nossa natureza de resistir a definições. Porque realmente não há algo absoluto em clown.

VILMA - A experiência acontece, não é algo que você pode explicar.

SUE - Exatamente, as pessoas querem falar sobre o processo mas a explicação não está aí, mas em fazer o trabalho, é como você tentar explicar uma piada, você a mata. Então digo novamente, o Richard era adorável porque ele nunca foi dogmático com o trabalho, ele não tinha uma coisa concreta de como ia ser ensinado e usado, porque eu tenho pessoalmente um problema com a teoria, e ele sempre me deu possibilidades. Eu não sei se eu aprendi muito sobre palhaço com o Richard mas eu acho que eu aprendi muito sobre ensinar, porque uma das coisas que eu aprendi foi como ensinar, porque as outras coisas vêm junto, mas partir das pessoas, a questão verdadeira é o como.

VILMA - Uma das últimas coisas que eu gostara de perguntar a você é como você se sente, porque você trabalha usualmente com pessoas de todo o mundo, de diferentes lugares, eu sinto como se fosse uma plantação e que eles vão espalhando. Como você vê isso? Como você se sente? Como é esse trabalho? 
SUE - Bem, é isso. É exatamente isso. As pessoas pegam, usam, trabalham de uma maneira boa para elas e um dia nós vamos estar em todo o mundo, basicamente (todo mundo ri) .

As culturas são únicas, mas por de baixo há sempre algo que é igual, no fundo é tudo sobre o amor e sobre a conexão. Quando você ultrapassa o comportamento cultural você chega a humanidade... Bem, e eu quero dizer que eu sou muito grata a Veronica, porque ela me disse "- Se você não escrever este livro alguém vai escrever. Então é melhor que você escreva." Então se não fosse a Verônica, eu não teria feito. Obrigada Veronica, mas eu nunca li o livro.

VILMA - Ontem quando nós tivemos a Soireé7 eu me peguei assistindo você porque eu fiquei fascinada pelo processo, mas pela maneira que você ensina.

SUE - Meu constante desejo de controlar tudo (ela ri).

VILMA - O trabalho é difícil por ele mesmo por sua natureza. Mas mesmo sendo intenso, você tem uma maneira de conduzi-lo e de lidar com as pessoas que é muito carismático, mesmo quando você é firme, não é um peso para desconstruir, para quebrar, mas para construir.

SUE - Exatamente. Porque algumas vezes eu penso que as pessoas quando trabalham com um estudante talvez façam uma piada com o trabalho de um aluno. Eles trabalham com uma maneira que é pesada para o aluno, mas o que o aluno tem que perguntar é "- Isso é para me fazer menos ou me fazer mais?" É preciso responder a essa pergunta. Também está prestes a criar uma tensão, não atenção, mas você tem que criar tensão e você tem que reconhecer quando você tem que quebrar essa tensão. Quando há muita tensão você tem que quebrá-la para liberar o quarto, porque o palhaço é sobre a liberação, transformação e liberação, você tem que saber como construí-lo, construir tensão e, em seguida, quando e o momento de liberar essa tensão.

Mas eu quero dizer que o ambiente de ensino deve ser de suporte, você precisa criar apoio dentro da sala. Eu vim de aulas com a comédia onde havia muita competição, você não queria ver alguém fazendo bem, porque talvez isso significasse que você não fez tão bem, eu sobrevivi trabalhando neste teatro improv. Eu não encontrei apoio e assim a coisa começou a ficar menor. Mas para criar este ambiente de apoio, isso era importante para mim, eu acho que isso veio da minha própria sobrevivência em diferentes grupos, e não como apoio falso, mas para dizer que pode ter sido uma porcaria, mas você ainda é uma boa pessoa, eu quero que você tente novamente. Porque este apoio falso é muito perigoso. A primeira vez que eu 
comecei a ensinar, o Richard tinha falecido, eu deixei passar um ano e então ele veio uma noite e ele me ensinou. Ele me visitou, não foi um sonho e ele nunca me deixou trabalhar sozinha, realmente. Sem Richard eu não poderia estar aqui. Foi como voltar para casa. Então eu trabalhei como performer e professora porque eu não posso trabalhar de uma maneira que não seja essa. 